\title{
II. NOTAS
}

\section{PERFORMATIVIDAD LÚDICA Y ESPACIOS DE GÉNERO EN RAYUELA Y EL TÚNEL}

\author{
Eduardo Barros Grela \\ Universidad de Coruña \\ ebarros@udc.es
}

Palabras ClaVe: performatividad, Cortázar, Sábato, narratología, multiplicidad.

KEY WORDS: Performativity, Cortázar, Sábato, Narratology, Multiplicity.

"Usted merecería escribir como habla, Perico.

Lo primero que atinó a decir Perico fue: 'Coño, mujer, ¿pero qué puñetería es ésa?',

La Maga, Oliveira y Perico Cuaderno de Bitácora de Rayuela

La articulación en un solo estudio -por amplio que éste sea- de la obra de autores tan divergentes como Julio Cortázar (1914-1984) y Ernesto Sábato (1911-2011) debe hacerse con extrema precaución al tratarse de autores cuyos aparatos epistemológicos fundamentales son, ciertamente, distantes (Davis 62). En concreto, las dos obras que se utilizarán en este estudio como punto de partida para la posterior discusión de las actuaciones de género -Rayuela (1963) y El Túnel (1948)- pertenecen a épocas relativamente distantes entre sí, tanto cronológica como socialmente. Sin embargo, no deja de ser significativo -por lo evidente- el gran número de coincidencias narratológicas halladas en la estructura profunda de estas dos novelas, que trascienden los límites de la textualidad y muestran una tendencia a perforar -como veremos en este estudio- los límites de las esferas de 
la discursividad y la paratextualidad ${ }^{1}$ para tratar el polémico tema del género ${ }^{2}$ en su vertiente más - podríamos decir- problemática $^{3}$.

Tanto la obra de Cortázar como la de Sábato privilegian la posición de sus protagonistas masculinos situándolos como paradigmas del sujeto actante, en un clara referencialidad a la de los propios narradores extradiegéticos. Tal preponderante estatus de los principales agentes de la función narratológica es enfatizada -en contraste- por la persistente cosificación a la que son sometidos los personajes femeninos en ambas novelas (en este caso concreto, las dos mujeres que acompañan a los protagonistas, Lucía ("La Maga") y María). La mera descripción de las mujeres como objetos observados/pensados por parte de los protagonistas masculinos (y masculinizantes) implica desde el inicio de ambas novelas una neutralización del actante femenino, así como una apropiación de su capacidad performativa a partir de la invisibilización de su subjetividad (Chatzivasileiou 413). Dados estos condicionantes, este estudio encuentra necesario plantear una indagación crítica sobre la intencionalidad narrativa de ambos protagonistas en referencia a esa reificación del sujeto femenino. Para ello, se examina la posibilidad de distanciarse de la crítica establecida sobre la aparente misoginia de estas dos novelas - sobre todo, Rayuela - mediante una lectura alternativa en la que las voces autoriales se insertan en la narrativa para habilitar la actuación performativa de los personajes femeninos. Desde esta visión, es clave la técnica de utilizar la mirada de los narradores para incorporar la subjetividad femenina a un discurso diegético en permanente deconstrucción, y crear así un espacio descentralizado en el que convergen las diferentes entidades narratológicas en un orden horizontal y no jerárquico.

1 En su uso del elemento paratextual, este estudio sigue las palabras de Genette (1997): “ ...the paratext is, rather, a threshold, or -a word Borges used apropos of a prefacea "vestibule" that offers the world at large the possibility of either stepping inside or turning back. It is an "undefined zone" between the inside and the outside, a zone without any hard and fast boundary on either the inward side (turned toward the text) or the outward side (turned toward the world's discourse about the text), an edge, or, as Philippe Lejeune put it, "a fringe of the printed text which in reality controls one's whole reading of the text" (2).

Tan solo un ejemplo de esta controversia serían las palabras de Andrew Brown con las que cita a Larsen: "Larsen (59) notes in particular what he sees as the novel's archaic views on gender, emphasizing not only Cortázar's lector hembra, (a phrase for which he subsequently apologized), but the apparent misogyny that runs through the text" (392).

Aquí sigo las consideraciones de Linda Hutcheon (1986): "The modes of this paradoxical incorporation are frequently those of paratextuality: footnotes, subtitles, prefaces, epilogues, epigraphs, illustrations, photographs, and so on. The problematizing of the process and status of documentation is perhaps inherent in the very nature of these paratextual modes, defined by Gérard Genette, as 'types de signaux accessoires [...] qui procurent au texte un entourage (variable) et parfois un commentaire, officiel ou officieux, dont le lecteur le plus puriste et le moins porté à l'érudition externe ne peut pas toujours disposer aussi facilement qu'il le voudrait et le pretend", (306). 
Se trata, desde luego, de una visión arriesgada en la que los elementos paratextuales de las novelas, en este caso las voces autoriales como herramientas de la ficción -y ellas mismas como ficción- tendrán una repercusión directa en el establecimiento de las narrativas como formas de expresión espacial de las identificaciones ${ }^{4}$ generadas por los personajes. En la obra de Cortázar se observan numerosas referencias implícitas a este procedimiento narrativo:

- ¿Todo eso te sucedió? - dijo Oliveira.

- Claro -dijo Gekrepten-. ¿No ves que se lo estoy contando a Talita?

- Son dos cosas distintas.

-Ya empezás, vos.

-Ahí tenés -le dijo Oliveira a Traveler, que lo miraba cejijunto-. Ahí tenés lo que son las cosas. Cada uno cree que está hablando de lo que comparte con los demás.

- Y no es así, claro - dijo Traveler. Vaya noticia.

- Conviene repetirla, che.

- Vos repetís todo lo que supone una sanción contra alguien.

-Dios me puso sobre vuestra ciudad -dijo Oliveira.

—Cuando no me juzgás a mí te la agarrás con tu mujer.

- Para picarlos y tenerlos despiertos -dijo Oliveira.

- Una especie de manía mosaica. Te la pasás bajando del Sinaí.

-Me gusta - dijo Oliveira- que las cosas queden siempre lo más claras posibles. A vos parece darte lo mismo que en plena conversación Gekrepten intercale una historia absolutamente fantasiosa de un dentista y no sé qué pollera. No parecés darte cuenta de que esas irrupciones, disculpables cuando son hermosas o por lo menos inspiradas, se vuelven repugnantes apenas se limitan a escindir un orden, a torpedear una estructura. Cómo hablo, hermano.

- Horacio es siempre el mismo -dijo Gekrepten-. No le haga caso, Traveler (212).

Aquí se aprecia bien la relación entre la realidad presentada y la realidad representada de los personajes que configuran el entramado narrativo de las dos novelas sometidas a estudio. Con este guiño a la relativización de las identidades expuestas de los personajes, que es tan meridiano en la obra de Cortázar, el autor argentino parodia insaciablemente la figuración del narrador como actante significativo en su novela. Las digresiones que intercala Gekrepten a las que hace referencia el narrador, siempre burladas desde una óptica narrativa heredera del más incisivo Sterne (Jaffe 210), adquieren un papel determinante en la propuesta lúdica del escritor argentino, que posiciona a su lector no solo en un hábitat espacial fronterizo entre la actuación (o performance) y lo representado, sino que permite suspicacias hermenéuticas de identificación entre los personajes que adquieren voz desde la parodia por un lado, y los propios lectores de su obra por otro ${ }^{5}$.

$4 \quad$ Entendidas éstas como los procesos sociológicos y, en este caso, narrativos, a partir de los cuales la identidad es imaginada y actuada. Véase Sandoval-Sánchez.

En el pasaje de Rayuela que se muestra como ejemplo, se observa la paródica identificación entre el lector y Talita, como generadora de espacios interpretativos de cuestionable 


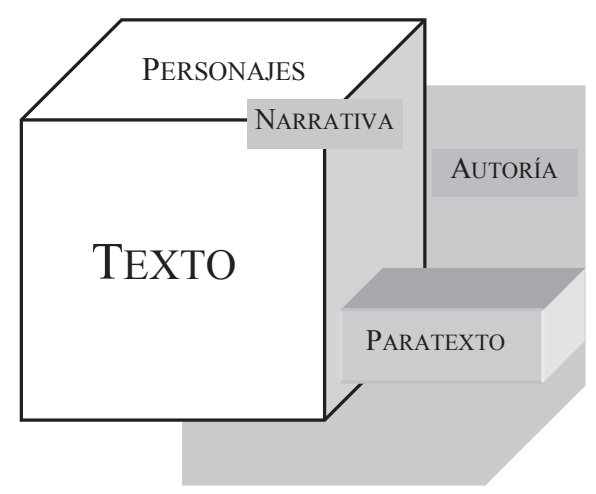

Fig. 1. Interferencias del discurso paratextual

No resulta baladí el hecho de que la vinculación entre las dos novelas sometidas a estudio tenga una base fundamental -desde el prisma analítico de este artículo- en la dialéctica de poder entre el sujeto masculino de la mirada y el objeto femenino como fetiche de la observación. Se plantea en este estudio que tanto el estatus social de las mujeres representadas como la función del tipo de relación narratológica que se establece en estas dos novelas deben ser problematizados, con el fin de cuestionar el supuesto legitimado por la crítica (Garfield, Paley, Mora) de que estas dos novelas utilizan a sus protagonistas masculinos para trazar -desde su hegemonía ontológica- una apropiación identitaria de las protagonistas femeninas.

El modelo estético que permite cuestionar estos supuestos sintoniza con los argumentos teóricos sobre la performatividad que Judith Butler explica en Gender Trouble (1990) primero, y en Bodies that Matter (1993) después. Esta conexión entre la obra de Butler y las de Cortázar y Sábato, probablemente causada por su necesidad empírica común, busca una desestabilización de las categorías establecidas -también de género-, con el fin de representar (enact) una discursividad ajena a la "naturalidad intuitiva femenina" legitimada por los ejercicios patriarcales de poder (Butler, Gender 177). En Bodies that Matter, Butler explica la funcionalidad del concepto de performatividad a la que me estoy refiriendo:

validez. Dada la estructura de la obra, no cabe suponer por parte del autor otra motivación más que la burla hacia Horacio como garante de la correcta interpretación del texto. Esa "manía mosaica" a la que se refiere Traveler, así como la referencia al pensamiento socrático pronunciada por el propio Horacio sobre su persona ("Dios me puso sobre vuestra ciudad") inciden en la particular necesidad del narrador por mantener despiertos a sus contertulios por medio de la continua provocación de sus argumentos, refracción a su vez de la misma actitud autorial de cara a sus lectores por medio de las continuas reificaciones del sujeto femenino. 
Sex is always produced as a reiteration of hegemonic norms. This productive reiteration can be read as a kind of performativity. Discursive performativity appears to produce that which it names, to enact its own referent, to name and to do, to name and to make. Paradoxically, however, this productive capacity of discourse is derivative, a form of cultural iterability or rearticulation, a practice of resignification, not creation ex nihilo. Generally speaking, a performative functions to produce that which it declares. As a discursive practice (performative "acts" must be repeated to become efficacious), performatives constitute a locus of discursive production (107).

Interesan particularmente las impresiones de Butler, sobre todo, a partir de esa paradoja que menciona. Siguiendo el procedimiento deconstructivo del lenguaje de Derrida, Butler se refiere a la performatividad como una forma de "iterabilidad cultural" que no puede existir sin la característica de la repetición como forma integrante fundamental (Hutcheon 93). En el texto de Cortázar observamos esa capacidad performativa desde su narrativa que hace uso de la parodia para interrogar las categorías narrativas establecidas. La iteración derrideana se explota en Rayuela no solo desde la paratextualidad, sino también desde la intertextualidad paródica, que parece expandir la idea de que las representaciones presentes vienen de representaciones del pasado, y que sus consecuencias ideológicas se derivan tanto de la continuidad como de la diferencia. En el pasaje citado anteriormente se observa que la referencia a Sócrates se realiza por medio de una acusada descontextualización de sus connotaciones, con lo que el proceso paródico y pseudoreiterativo se desprende en un acto performativo (in/ad)verso, que declara y desmiente a la vez sus postulados discursivos, haciendo de su función narrativa el epítome de la paradoja anunciada por Butler.

Otro aspecto en el que coinciden Butler y los autores de Rayuela y El túnel es en su crítica del logocentrismo (en palabras de Butler, del falogocentrismo) y su conexión con la materia. Horacio Oliveira insiste no solo en repetir sus diatribas contra la identificación del discurso con su representabilidad, sino en la necesidad de reiterar esa crítica ("-Conviene repetirla, che", op. cit.). El acto performativo inverso que subyace a la intervención autorial de Cortázar en el discurso de Horacio es el de dotar de validez al acto discursivo de Gekrepten, así como exponer la naturaleza falsificada de sus propias palabras. Así, cuando menciona que las irrupciones discursivas de Gekrepten, sus digresiones, son "repugnantes" por limitarse a interrumpir un discurso, Horacio está desplazando el elemento paródico de su propia narrativa hacia la discontinuidad discursiva de su compañera, en un recurso paratextual que parte de la implicación hegemónica del autor como elemento deconstructor de la parodia, y que pone bajo interrogante las connotaciones directas que su narrativa proyecta sobre la representación de la mujer.

En el caso de El Túnel, la relación entre Castel y María se va conformando ante la mirada del lector, efectivamente, a medida que ambos protagonistas avanzan en la verbalización de sus propias identidades (Hunter 670). El efecto paródico de Sábato sobre la representabilidad de la subjetividad de María a partir de un proceso de traslación desde el logos de Castel se observa claramente en el pasaje que sigue: 
María me miró con mayor tristeza. Estuvo un rato callada y al cabo me preguntó con voz muy dolorida:

- ¿Es necesario que responda también a eso?

- Sí, es absolutamente necesario - le dije con dureza.

- Me parece horrible que me interrogues de este modo.

- Es muy sencillo: tienes que decir sí o no.

- La respuesta no es tan simple: se puede tener y no tener.

- Muy bien - concluí fríamente - . Eso quiere decir que sí. [...].

- Muy bien: sí.

- Entonces lo deseas.

- He dicho que tengo relaciones con él, no que lo desee.

- ¡Ah! - exclamé triunfalmente - ¡ Eso quiere decir que tienes relaciones sin desearlo pero haciéndole creer que lo deseas! (58).

A partir de un desplazamiento semántico de la discursividad de María, Castel se apropia de su subjetividad al fagocitar la denotación presente en las palabras de María, alienando a ésta de su propio discurso. Castel es incapaz de funcionar en el universo semántico de María - como le pasaba a Horacio con La Maga-, cuyo espacio está definitivamente alejado del de la caótica -aunque fundamentalmente estructurada- epistemología de Castel (Abella 17), y que produce una disfunción en la organización lógica de los acontecimientos del protagonista masculino, que se ve así forzado a reinterpretar las palabras de María según su particular hermenéutica. El efecto paródico producido por la repetición de los argumentos en este procedimiento performativo revela, por lo tanto, un distanciamiento entre el personaje de Castel y su voz narrativa, en la que la intromisión autorial es evidente como recurso para evidenciar ese mismo efecto paródico.

Así, la argumentación de Butler en torno a la performatividad proporciona una herramienta crítica fundamental para Rayuela y El Túnel. La posibilidad de releer estos textos a partir de una función paródica de la performatividad de sus participantes implica el cuestionamiento de la relación establecida entre ambos autores y sus obras literarias, y permite aproximarse a las relaciones de género de sus personajes desde una óptica diferente a la establecida por la crítica reciente (Muratore, Ferreira).

La deconstrucción de los elementos binarios en la relación hombre-mujer se representan en El túnel y en Rayuela a través de la falaz suposición de que los personajes femeninos responden a las visiones masculinizantes de sus respectivos autores. Este tipo de relación se podría extrapolar a espacios y dinámicas alejadas del campo de la ficción mediante la inversión -y la subversión- de esas relaciones. La función performativa de la voz de los personajes a partir del elemento paratextual de la intervención autorial implícita ${ }^{6}$ admite la construcción de La Maga y de María como sujetos agentes de su propia identidad, más allá de sus representaciones a través de las miradas de los narradores de las novelas. Abandonan, así, sus posturas como personajes inertes, sin agencialidad, que son 
narrados por una voz diegética externa y hegemónica, y adoptan en cambio una posición autónoma en la diégesis, con agencialidad propia y capacidad plena de identificación. Es representativo de este proceder el pasaje de Rayuela en el que La Maga se confiesa incapaz de expresarse adecuadamente, algo que es inmediatamente rectificado por su expresiva mirada de perplejidad hacia los argumentos de Gregorovius:

-Yo no me sé expresar - dijo la Maga secando la cucharita con un trapo nada limpio-. A lo mejor otras podrían explicarlo mejor pero yo siempre he sido igual, es mucho más fácil hablar de las cosas tristes que de las alegres.

-Una ley -dijo Gregorovius--. Perfecto enunciado, verdad profunda. Llevado al plano de la astucia literaria se resuelve en aquello que de los buenos sentimientos nace la mala literatura, y otras cosas por el estilo. La felicidad no se explica, Lucía, probablemente porque es el momento más logrado del velo de Maya.

La Maga lo miró, perpleja (24).

Las iniciales descripciones que Castel ofrece de María en la novela de Sábato dan impresiones similares:

—Necesito mucho de usted -repetí. No respondió: seguía mirando el árbol.

— ¿Por qué no habla? -le pregunté. Sin dejar de mirar el árbol, contestó:

-Yo no soy nadie. Usted es un gran artista. No veo para qué me puede necesitar.

Le grité brutalmente:

— ¡Le digo que la necesito! ¿Me entiende? Siempre mirando el árbol, musitó:

- ¿Para qué?

No respondí en el instante. Dejé su brazo y quedé pensativo. ¿Para qué, en efecto? Hasta ese momento no me había hecho con claridad la pregunta y más bien había obedecido a una especie de instinto. Con una ramita comencé a trazar dibujos geométricos en la tierra.

-No sé - murmuré al cabo de un buen rato-. Todavía no lo sé.

Reflexionaba intensamente y con la ramita complicaba cada vez más los dibujos.

- Mi cabeza es un laberinto oscuro. A veces hay como relámpagos que iluminan algunos corredores. Nunca termino de saber por qué hago ciertas cosas. No, no es eso... (17).

Ambos narradores comparten los mismos parámetros ontológicos hacia el cuerpo femenino: la percusión de la realidad de las mujeres sobre la representación de éstas produce, tanto en los narradores como en los personajes masculinos en los que aquéllos se proyectan, una incomodidad existencial resultante de la sublevación del Otro, es decir, de la perplejidad del subalterno ante el discurso de poder y dominación del pensamiento hegemónico ${ }^{7}$. La

$7 \quad$ Véase Dussel (2009), donde se expone de forma explícita una definición del componente de la Política de la Liberación que se encuentra presente en gran parte de su obra y, particularmente, en la aquí referenciada, en la que se observa la fundamentación básica del paradigma ideológico implícito en este estudio: “... se debía generar un nuevo discurso (c'), desde la peculiaridad de los oprimidos y excluidos, los pobres, el pueblo latinoamericano. Así nació la Filosofía de la Liberación. Después, a mediados de la década de los setenta, dicho 
profunda erudición de los narradores masculinos parece no comprender las actuaciones de los personajes femeninos, cuya performatividad entra en acción tras una compleja combinación de sus voces, las de los narradores (parodiadas) y las de los autores (interviniendo desde la paratextualidad mediante una confusión de las fronteras narratológicas).

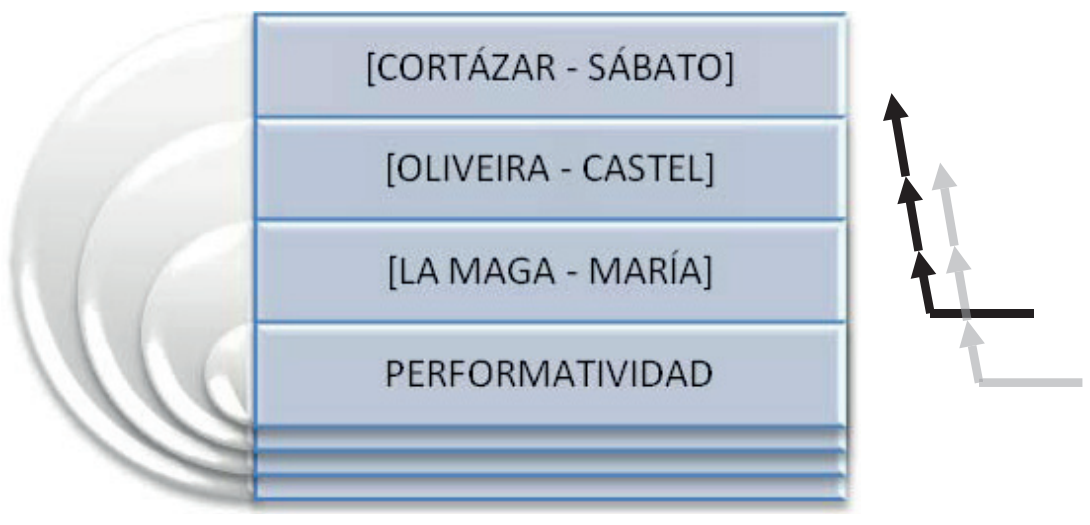

Fig. 2. Modelo tradicional (jerárquico) de las relaciones de representación y performatividad en Rayuela y El túnel.

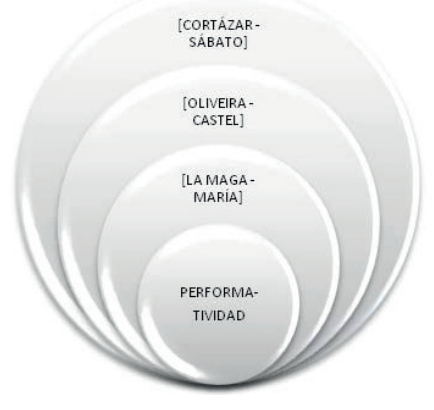

Fig. 3. Modelo "horizontal" (no jerárquico) propuesto. Se aplica el concepto de "exterioridad" de Dussel al esquema de "totalidad" presentado en El Capital.

discurso sobrepasa el horizonte latinoamericano y se va desplegando en otros continentes oprimidos (África y Asia), entre los movimientos populares, clasistas, ecologistas, feministas (Filosofía feminista de la Liberación) [...] en la lucha contra el racismo, etc., y se toma conciencia de que se trata de una filosofía que debe asumir pretensiones de «mundialidad» (se pasa de $c$ ' a d', $\left.e^{\prime}, n\right)$, porque hay oprimidos y excluidos en todos los sistemas existentes" (65). 
Esta amalgama de intenciones se refleja en varios pasajes clave de las obras, como el que utiliza Castel para ofrecer otra descripción de María también en las páginas iniciales de la novela de Sábato:

Una tarde, por fin, la vi por la calle. Caminaba por la otra vereda, en forma resuelta, como quien tiene que llegar a un lugar definido a una hora definida. La reconocí inmediatamente; podría haberla reconocido en medio de una multitud. Sentí una indescriptible emoción. Pensé tanto en ella, durante esos meses, imaginé tantas cosas, que al verla, no supe qué hacer (7).

Se observa en este fragmento de El túnel la presencialidad subjetiva de María, en su caminar de reterritorialización ${ }^{8}$, junto a la apropiación que Castel hace de su representabilidad al sustituir la performatividad de su cuerpo en movimiento por la reimaginación que él propone de su espacialidad ("La reconocí inmediatamente; podría haberla reconocido en medio de una multitud. Sentí una indescriptible emoción. Pensé tanto en ella, durante esos meses, imaginé tantas cosas...”) A estas dos líneas discursivas se une la autoría implícita de Sábato en formación paródica, que se hace explícita en las palabras finales del texto resaltado en esta cita.

El responsable de la narración en Rayuela no ofrece una mejor aproximación a la experiencia femenina de lo que lo hace el narrador de El túnel:

- No vuelvas, dijo La Maga.

-En fin, no exageremos, dijo Oliveira...

- Te tengo tanta lástima, Horacio...

—Ah, eso no. Despacito ahí...9 (82).

Hay en estas líneas una evidente desautorización discursiva e identitaria por parte de Horacio hacia La Maga. La jerarquización categórica a la que el narrador ha sometido a sus personajes mediante la potente semantización de su discurso queda, sin embargo, en evidencia ante la crudeza retórica de La Maga ${ }^{10}$, que ridiculiza el barroco proceder del responsable de la narrativa.

8 En el sentido deleuzeano de reapropiarse de un espacio o territorio.

9 Mi énfasis.

10 Madrid (1991) afirma que existe una querencia por parte de Horacio Oliveira a alcanzar una identificación asimiladora por medio de una vejación sistemática de la voz de La Maga: "She is ignorant but endowed with the wisdom of intuition, that prevents her from being comprehended by the rational Other. Horacio Oliveira understands all of this. Nevertheless, he despises La Maga. So, the reader wonders whether his quest for heaven (kibbutz of desire, yonder, final island, change) does not ultimately imply the disappearance of differences, that is, the achievement of the identical" (330). No obstante, el aparato lúdico de Cortázar parece sugerir una celebración de las diferencias que separan al personaje protagonista de La Maga, ya que desde su incapacidad para acceder a la intuitiva performatividad de su compañera, 
Tanto Castel como Horacio son narradores condescendientes con sus personajes, y ejercen su poder para producir -desde su matriz patriarcal- un determinado rol para las mujeres protagonistas. Una vez que han creado una plantilla femenina en el desarrollo de sus narrativas, Castel y Oliveira la rellenan con objetos femeninos cuya actuación performativa quedaría restringida a los mismos límites que soportan sus contenedores estructurales, unos límites que se corresponderán con el papel de mujer para la mujer y de hombre para el hombre, preasignados de forma lúdica desde la narración (Rodríguez, Alasraki, Yurkievich). Este rasgo es claramente visible en las conversaciones entre Oliveira y Gregorovius:

— ¿La Maga hizo alguna insinuación de que se iba a matar?

-Bueno, las mujeres, ya se sabe.

- Concretamente.

- No creo -dijo Gregorovius-. Insistía más en lo de Montevideo.

-Es idiota, no tiene un centavo.

- En lo de Montevideo y en eso de la muñeca de cera.

$[\ldots]$

— Odio la estupidez - dijo virtuosamente Oliveira (Rayuela 142-3).

Los narradores de estas dos novelas responden claramente a la tipología actancial propuesta por Greimas a finales de los años 60. Definiendo las entidades de una pieza literaria a partir de los diferentes niveles de significación desde lo actuacional, interesan para este estudio los apartados que tratan las características de los actantes, a los que se refiere Greimas como las categorías permanentes que construyen la estructura diegética en el nivel de los personajes, y los diferentes actores para cada construcción narrativa. La función performativa de estos actores no es, evidentemente, la de sujetos libres, ya que están plenamente condicionados por los roles preasignados que toda obra literaria conlleva intrínsecamente, de acuerdo con Greimas.

Esta teorización dentro del campo de la semiótica surge de una concepción lingüística basada en las dos categorías del significado y el significante. Cortázar y Sábato utilizan de forma lúcida este atributo para la creación de sus narradores-personajes con el fin de referirse a un desplazamiento de las correspondencias atribuidas a los dos componentes del signo lingüístico, en consonancia con las reflexiones teóricas de Jacques Derrida sobre la pertinencia de tales asociaciones (différance). Los autores de Rayuela y El túnel introducen en el discurso narrativo su propia perspectiva como parte de la propuesta lúdica

Horacio se reconoce como fuerza dominante del discurso, pero como pieza sometida en su comprensión de los espacios que les son comunes:

-No seas tonto, Horacio, te digo que no me he acostado con él. ¿Te tengo que hacer el gran juramento de los sioux?

-No, al final me parece que te voy a creer.

-Y después - dijo la Maga- lo más probable es que acabe por acostarme con Ossip, pero serás vos el que lo habrá querido (Rayuela 71). 
que presentan, permitiendo al lector comprender la doble intencionalidad en las palabras de sus narradores. Estos autores juegan, así, con la responsabilidad de las relaciones entre el significado y el significante, entre los actores y los actantes, y finalmente, entre los roles y los personajes.

Uno de los mejores ejemplos que se pueden encontrar en Rayuela para demostrar esta argumentación es el uso que hace Cortázar del propio lenguaje. El público lector puede encontrar fácilmente a través de la novela numerosas muestras de la problematización de las relaciones entre significado y significante como vehículo para problematizar las representaciones de género. "Otro suisida", uno de sus más conocidos pasajes en Rayuela, perfectamente demuestra los límites de los roles asignados para los mencionados pares binarios. Cortázar desintegra las pre-supuestas relaciones entre significado y significante mediante una alteración del primero que no afecta a la referencialidad del segundo: “Ingrata sorpresa fue leer en 'Ortográfiko' la notisia de aber fayesido en [...] Sorpresa fue porke no teniamos notisia de ke se ayara en kama...” (Rayuela 306). También el conocido ejemplo del "glíglico" (Yovanovich 548), un juego inventado por La Maga en el que se mantienen los significados de las palabras aun con un significante que solo recuerda al original en una suerte de aroma, sirve el mismo propósito. El tono, el ritmo y la sonoridad del discurso son suficientes para expresar significado, lejos de la estructuración lógica de la complementariedad del signo, tal y como afirmó Roland Barthes en referencia a la relaciones sígnicas (46): “Apenas él le amalaba el noema, a ella se le agolpaba el clémiso y caían en hidromurias, en salvajes ambonios, en sustalos exasperantes..." (Rayuela 305).

La ruptura de los modelos binarios de significado-significante en estos fragmentos cruciales de la obra de Cortázar da pie al cuestionamiento de éstos en otros niveles textuales como los que se han expresado al inicio de este ensayo y que aparecen ilustrados en los gráficos adjuntos (figs. 1, 2 y 3), incluyendo los referidos a la prominente relevancia de la paratextualidad. Como parte integrante del juego que Cortázar plantea a sus lectores -y que se halla ya dibujado en el propio título de la novela, como es bien sabido- se presenta la transmisión de diferentes entidades narrativas entre los distintos niveles de estructuración textual. Su propuesta es la de fragmentar los límites que separan esos distintos niveles para permitir que los rasgos particulares de cada uno de esos espacios discursivos perforen las lindes textuales y penetren esos otros dominios en una suerte de descontextualización paródica (Hutcheon) de las categorías de despersonalización del sujeto (Greimas, Todorov) o reterritorialización de los procesos de identificación discursiva (Deleuze).

Por lo tanto, el cuestionamiento de determinados valores de la relación entre el significado y el significante en esta obra trasciende sus límites lingüísticos. Al traspasar las líneas fronterizas entre las diferentes dimensiones interpretativas, y adentrarse en los dominios de lo semiótico, de lo narratológico y de lo paratextual, Cortázar y Sábato permiten este mismo tránsito categórico en el ámbito de la subyugación de los actores a determinados actantes del cuadro tipológico greimasiano, y en el de la subyugación de los personajes femeninos a los roles previamente producidos por las miradas masculinas de los narradores. 
En eso consiste el principal elemento lúdico en la narrativa de estos dos escritores argentinos: emplean un juego conceptual que va más allá de las actividades puramente expresivas actuadas por los personajes, y superan incluso las metas de sus estratagemas iniciales, al sugerir ciertas pistas conductoras a un lector de quien se espera que las extrapole a los diferentes dominios que conforman la estructura de las novelas.

Uno de esos dominios, tal y como ya se ha anticipado, es el de la relación entre actores y actantes. Directamente relacionado con el de la relación entre narradores y personajes, en este nivel textual se observa -como ya se ha mencionado con anterioridad- una tendencia a percibir dentro de la propia historia propiedades de las intenciones originales del autor con respecto a su (des)estructuración de los elementos narrativos. Por un lado, en Rayuela, la presencia en el texto de dos mundos diferenciados (“del lado de allá", París (5) y "del lado de acá”, Buenos Aires (175)) en los que los personajes desarrollan sus personalidades condicionados por su situación espacial socava en sí la hegemonía de las identidades sólidas y bien establecidas, así como sus papeles en determinados espacios. La Maga, por ejemplo, es un personaje cuya espacialidad aparece representada en todos los personajes de la novela, con los que comparte diversas funciones actanciales dependiendo del espacio en el que se encuentre (sea éste físico o no.)

Otro dominio de importancia que aparece problematizado con esta ruptura de las fronteras espaciales es el que relaciona a los personajes con los narradores. En el caso de las obras que se someten aquí a estudio, estas entidades narrativas adquieren un valor añadido, al ser consideradas como fundamentales en la reificación intencional del objeto que es narrado desde la posición hegemónica del sujeto actante narrativo, cuya entidad diegética es de alto poder discursivo (Tcherepashenets, Sieber): "Hay ríos metafísicos. Sí, querida, claro. Y vos estarás cuidando a tu hijo, llorando de a ratos, y aquí ya es otro día y un sol amarillo que no calienta" (Rayuela 86). "Y entonces, mientras yo avanzaba siempre por mi pasadizo, ella vivía fuera su vida normal, la vida agitada que llevan esas gentes que viven afuera, esa vida curiosa y absurda en que hay bailes y fiestas y alegría y frivolidad" (El túnel 64.) De nuevo, los autores construyen a sus narradores como entidades fijas que producen formas ficcionales también fijas, acordes a sus imaginaciones de la mujer como objetos representados. Cortázar y Sábato, a partir de narradores que van produciendo los personajes a medida que los van contando, parodian así las concepciones narratológicas establecidas. La Maga, tal y como aparece representada en la novela, no es La Maga más que en la reimaginación de Horacio como proyección de su escritura hacia ella. María también se parece alejar en la narración de lo que un personaje con subjetividad orgánica plena pudiera parecer, y aparece ante los ojos del lector como una versión reimaginada del deseo no-satisfecho del pintor Castel.

Tanto Sábato como Cortázar han creado narradores que son muy parecidos entre sí en términos de funcionamiento. Ellos son los recipientes de las acciones que irrumpen en los espacios textuales consolidados, pero también quienes las reciben. Alejándose de las convenciones narratológicas en las que los narradores crean un papel performativo para sus personajes, en particular para las mujeres, el argumento implícito que presentan los autores de estas novelas es el de una agencialidad recíproca de la multiplicidad textual (personajes, narradores, autores), en la que los narradores producen una performatividad 
que emana de los personajes en la misma medida en la que éstos (-éstas-) crean una performatividad en los narradores con la complicidad de las voces autoriales implícitas ${ }^{11}$. En continuidad de esta propuesta hermenéutica, se podría completar la afirmación sostenida anteriormente con respecto a la interdependencia de personajes y narradores con la sospecha de que no solo La Maga y María son representaciones del imaginario creado por los narradores de las novelas, sino que éstos también son, en una estructuración narrativa desjerarquizada y rizomática, proyecciones de la imaginación de las protagonistas femeninas ${ }^{12}$.

Hay, sin embargo, un elemento fundamental que se deriva de tal argumentación: habría que establecer desde la hermenéutica del texto si tanto Cortázar como Sábato tenían en mente una estructuración rizomática -más que laberíntica- de la narrativa ${ }^{13}$. Es, desde luego, notorio que los autores escojan elementos espaciales particularmente descentralizados para crear la distribución narrativa de sus obras: en el caso de Rayuela, la imaginación espacial del juego que da título a la obra, así como la geografía representada en la novela; en el caso de El Túnel, la misma concepción del elemento al que se refiere el título de la obra, el túnel, que además de caracterizar la tan celebrada correlación psicoanalítica, atiende a una caracterización como inenarrable conexión entre diferentes espacios o espacialidades.

Esa confirmación textual se puede producir, en el caso de la novela de Cortázar, en las breves instrucciones "paratextuales" al inicio de la misma, bajo el epígrafe "Tablero de dirección":

11 Es evidente que, en tal argumentación, se problematiza la propia funcionalidad de la capacidad de actuación de las entidades narrativas implicadas, ya que su plasmación concreta depende directamente de la performatividad de otro agente externo, y de forma recíproca, con lo que se produce una paradoja óntica, plenamente congruente con el planteamiento lúdico de los escritores argentinos.

12 El ejemplo más conocido del proceso de la escritura de la identidad de La Maga por parte de Horacio es, sin duda, el correspondiente al capítulo 7 de Rayuela:

Toco tu boca, con un dedo toco el borde de tu boca, voy dibujándola como si saliera de mi mano, como si por primera vez tu boca se entreabriera, y me basta cerrar los ojos para deshacerlo todo y recomenzar, hago nacer cada vez la boca que deseo, la boca que mi mano elige y te dibuja en la cara, una boca elegida entre todas, con soberana libertad elegida por mí para dibujarla con mi mano en tu cara, y que por un azar que no busco comprender coincide exactamente con tu boca que sonríe por debajo de la que mi mano te dibuja (29).

El "azar que no busca comprender" es la clave lúdica del autor hacia la creación de los personajes en relación con las demás entidades narrativas. Tras afianzarse como creador de la identidad incluso corporal de La Maga, Horacio recurre al elemento paródico del azar para poner en duda su capacidad, e incluso su voluntad, de actuar como autor de un determinado personaje.

13 Es decir, si los conceptos de centralidad y exterioridad se hallaban ya en crisis para estos escritores. 
A su manera este libro es muchos libros, pero sobre todo es dos libros.

El primero se deja leer en la forma corriente, y termina en el capítulo 56, al pie del cual hay tres vistosas estrellitas que equivalen a la palabra Fin. Por consiguiente, el lector prescindirá sin remordimientos de lo que sigue.

El segundo se deja leer empezando por el capítulo 73 y siguiendo luego en el orden que se indica al pie de cada capítulo. En caso de confusión u olvido, bastará consultar la lista siguiente... (Rayuela, páginas preliminares).

La propuesta de reconfiguración espacial desde la narrativa de Rayuela es de sobras conocida $^{14}$, pero interesa en este caso prestar especial atención a la primera frase de este tablero de dirección: "A su manera, este libro es muchos libros". La lectura de Rayuela se somete, así, a una interacción descentralizada con los capítulos de la obra, lo que permite al lector desplazarse espacialmente desde la formulación arbórea tradicional de la(s) narrativa(s) hacia una propuesta rizomática que afecta a todos los elementos participantes en el proceso comunicativo de la novela. En el caso de los narradores, estos elementos pierden su centralidad como protagonistas en el peso específico de la ficción, y su medular presencia narrativa se diluye en una interacción descentralizada y dinámica con los personajes.

En el caso de El túnel, el estilo conversacional del narrador con sus lectores implícitos también invita a cuestionar la validez de la estructura narrativa jerarquizada. Cuando Sábato inicia su novela, citando a su propio narrador y personaje protagonista, está de nuevo cuestionando los valores fronterizos de los esquemas narrativos presentes en tipologías como la de Greimas ${ }^{15}$ : “...en todo caso, había un solo túnel, oscuro y solitario: el mío" (El túnel, páginas preliminares). Luego continúa, para dar comienzo a la voz narrativa de Castel: "Bastará decir que soy Juan Pablo Castel, el pintor que mató a María Iribarne; supongo que el proceso está en el recuerdo de todos y que no se necesitan mayores explicaciones sobre mi persona" (1). Su presentación como autor de la novela en referencia a un suceso del que los lectores han sido testigos es utilizada como herramienta narrativa para difuminar, insisto, las fronteras entre las diferentes entidades narrativas.

Tanto el túnel que conecta diferentes espacios, abriendo brechas en sus fronteras, como la piedra de la rayuela que ignora los límites de cada casilla, y sirve como anticipo del sujeto transgresor de espacialidades, son imágenes de los juegos identitarios presentes en ambas novelas. Las subjetividades puestas en funcionamiento con esta dinámica convergen en una multiplicidad espacial cuya esencia se encuentra en el movimiento mismo como antítesis de las estancias narrativas catalogadas, y que apuesta por una deontologización de los elementos actanciales del texto, y favorece la performatividad del sujeto femenino desde instancias paródicas de la narrativa, manifestadas a partir de la paratextualidad.

14 Para consultar detallados estudios sobre la estructura de la obra, véanse los trabajos de Tcherepashenets y Bocchino.

15 Algo que, por otro lado, ya se había experimentado con anterioridad, especialmente en la obra de Miguel de Unamuno. Para consultar un detallado informe sobre la influencia del escritor vasco en la obra de Sábato, véase el artículo de Hermosilla a este respecto. 
El juego narrativo propuesto por Julio Cortázar y Ernesto Sábato en Rayuela y El túnel afecta, por lo tanto, a todas las instancias participativas, incluyendo la de los propios escritores en su función de autores. Desde la problematización infraestructural del signo lingüístico en sus novelas, los autores inician un recorrido de transgresión de espacios narrativos que afectará en una escala paradigmática a las relaciones entre los personajes y los narradores, entre los narradores y los autores, y consecuentemente -y por vía de la paratextualidad- entre los autores y los personajes. En última instancia, esta propuesta lúdica busca hacer partícipes a los lectores de Rayuela y El túnel en el proceder identitario de la performatividad, cuya presencia fragmentada en el espacio narrativo de las obras se traslada al propio espacio óntico del lector, con lo que se transgreden de nuevo los compartimentos estancos de la narratividad propuesta.

Tal apuesta por una horizontalidad de las estructuras novelísticas facilita una agencialidad performativa para todos sus componentes, desde los lectores hasta los personajes -también los femeninos- e incide, así, en la multiplicidad discursiva como forma descentralizada -rizomática- de escritura identitaria.

\section{BIBLIOGRAFÍA}

Abella, Encarna. Sátira y parodia de la novela policial borgeana en El túnel de Ernesto Sábato: ensayo paródico interpretativo. Madrid: Editorial Eurolex, 2000.

Alasraki, Jaime. “Rayuela: Estructura”. Rayuela. Eds. Julio Ortega y Saúl Yurkievich. Madrid: Colección Archivos, 1991. 629-49.

Amestiy, Linda A. Cortázar, la Novela Mandala. Buenos Aires: Fernando García Cambeiro, 1972.

Barthes, Roland. La aventura semiológica. Trad. Ramón Alcalde. Barcelona: Editorial Paidós, 2009.

Bocchino, Adriana A. Caso Rayuela: las tramas de un ardid. Mar del Plata: Estanislao Balder, 2001.

Brodin, Brita. Criaturas ficticias y su mundo en Rayuela de Cortázar. Estocolmo: Studentlitteratur, 1975.

Brown, J. Andrew. "Reading Rayuela in the Rayuel-O-Matic". Revista Canadiense de Estudios Hispánicos 29/2 (2005): 379-396.

Butler, Judith. Bodies that Matter. New York: Routledge, 1993.

Gender Trouble: Feminism and the Subversion of Identity. New York: Routledge, 1990.

Chatzivasileiou, Litsa. "Rereading Rayuela: Hypergraphy, Hermaphrodism, and Schizophrenia". Revista Canadiense de Estudios Hispánicos 25/3 (Primavera 2001): 397-423.

Corral, Wilfrido H. "Novelistas sin timón: exceso y subjetividad en el concepto de "novela total' ". MLN 116/2 (Marzo 2001): 315-49.

Cortázar, Julio. Cuaderno de Bitácora de Rayuela. Buenos Aires: Editorial Sudamericana, 1983. Rayuela. Madrid: Colección Archivos, 1991.

Davis, Mary. The Vision of Reality in Selected Novels by Sábato, Cortázar, and García Márquez. Tesis Doctoral. University of Kentucky, Lexington, 1974. 
Deleuze, Gilles y Félix Guattari. Anti-Oedipus: Capitalism and Schizophrenia. Trad. Robert Hurley, et al. London and New York: Continuum International Publishing Group, 2004. A Thousand Plateaus. Trad. Brian Massumi. London and New York: Continuum International Publishing Group, 2004.

Derrida, Jacques. Of Grammatology. Trad. Gayatri Spivak. Maryland: The Johns Hopkins University Press, 1998.

Dussel, Enrique. Materiales para una politica de la liberación. México D.F.: Plaza y Valdés, 2009.

Escobar, María Eugenia. “Rayuela: ¿disyunción mítica o ambivalencia novelesca?” Acta Literaria 2 (1977): 57-8.

Ferreira, Ana Paula. "El Túnel de Ernesto Sábato. En busca del origen”. Revista Iberoamericana LVIII. 158 (Enero-Marzo 1992): 91-104.

Garfield, Evelyn Picón. Cortázar por Cortázar. Xalapa, México: Universidad Veracruzana, 1981.

Genette, Gérard. Palimpsestos. La literatura en segundo grado. Trad. Celia Fernández Prieto. Madrid: Taurus, 1982.

Paratexts: Thresholds of Interpretation. Trad. Jane E. Lewin. Cambridge: Cambridge University Press, 1997.

Giacoman, Helmy. Los personajes de Sábato. Buenos Aires: Emecé Editores, 1972.

Greimas, Algirdas. Structural Semantics: An Attempt at a Method. Trad. Daniele McDowell, Ronald Schleifer y Alan Velie. Lincoln, Nebraska: University of Nebraska Press, 1983.

Hermosilla Sánchez, Alejandro. "Influencias de Miguel de Unamuno en Ernesto Sábato y el pensamiento argentino". Cuadernos Cátedra Miguel de Unamuno 44 (2-2007): 81-95.

Hunter, Robert A. "The Theme of the Sightless Asexual as Seen in the Novels Santa by Federico Gamboa and El túnel by Ernesto Sábato". Hispania 92/4 (Diciembre 2009): 664-72.

Hutcheon, Linda. The Politics of Postmodernism. New York: Routledge, 1989.

"Postmodern Paratextuality and History". Texte 5/6 (1986-87): 301-13.

Jaffe, J. A. Lovers 'play/l'oeuvre se plait: the love story in the digressive tradition of Sterne, Machado de Assís and Cortázar. Madison: University of Wisconsin Press, 1989.

Larsen, Neil. "Cortázar and Postmodernism”. Julio Cortázar: New Readings. Ed. Carlos Alonso. Cambridge: Cambridge UP, 1998. 57-75.

Lichtblau, Myron. Rayuela y la creatividad artistica. Miami: Ediciones Universal, 1988.

Madrid, Lelia. "La Maga or the Problem of Readership". Revista Canadiense de Estudios Hispánicos 15/2 (Invierno 1991): 328-33.

Mora, Gabriela y Karen S. Van Hooft (Eds.). Theory and Practice of Feminist Literary Criticism. Ypsilanti, Michigan: Bilingual Press, 1982.

Muratore, Mary. “Authorial Irrelevance in Sábato’s El Túnel”. Neohelicon 35/1 (2008): 205-19.

Paley Francescato, Martha. "The New Man (But Not the New Woman)". The Final Island. Eds. Jaime Alazraki e Ivar Ivask. Norman: University of Oklahoma Press, 1981. 134-39.

Quiroga de Cebollero, Carmen. Entrando a El túnel de Ernesto Sábato; análisis e interpretación. Río Piedras: Editorial Universitaria, Universidad de Puerto Rico, 1971. 
Read, Malcolm K. Transitional Discourses. Ottawa: Dovehouse Editions, 1998.

Rodríguez, Ileana y Raúl Antelo (Eds.). Cánones literarios masculinos y relecturas transculturales: lo trans-femenino/masculino/queer. Barcelona: Anthropos Editorial, 2001.

Sábato, Ernesto. El Túnel. Madrid: Cátedra, 1994.

The writer in the catastrophe of our time. Trad. Asa Zatz. Chicago: Independent Publishers Group, 1990.

Sandoval-Sánchez, Alberto y Nancy Saporta Sternbach. Stages of Life: Transcultural Performance \& Identity in U.S. Latina Theater. Tucson: University of Arizona Press, 2001.

Sieber, Sharon Lynn. "Fantastic Interpretations of Time in Juan Rulfo's Pedro Páramo, Julio Cortázar's Rayuela and José Lezama Lima's Paradiso: A Modern Continuity of the Baroque". Hispania 91/2 (Mayo 2008): 331-41.

Subirats, Eduardo. Ilustración insuficiente. Madrid: Taurus Ediciones, 1981.

Tcherepashenets, Nataly. Place and displacement in the narrative worlds of Jorge Luis Borges and Julio Cortázar. New York: Peter Lang, 2008.

Todorov, Tzvetan. The poetics of prose. Trad. Richard Howard. Ithaca: Cornell University Press, 1977.

Valcárcel, Eva (Ed.). Hispanoamérica en sus textos. A Coruña: Universidade da Coruña, 1993.

Yovanovich, Gordana. "The Role of Women in Julio Cortázar's Rayuela”. Revista Canadiense de Estudios Hispánicos 14/3 (Primavera 1990): 541-52.

Yurkievich, Saúl. “La pujanza sumisa”. Ortega y Yurkievich, opus cit. (661-75). 